\title{
El Valle del Zújar: un importante enclave para el arte rupestre esquemático en Badajoz
}

\author{
M. ${ }^{a}$ Isabel Martinez Perello*
}

\begin{tabular}{|c|c|}
\hline RESUMEN & ABSTRACT \\
\hline $\begin{array}{r}\text { En el Valle del Zújar, } \\
\text { al Este de la provincia }\end{array}$ & $\begin{array}{l}\text { In the Valley of Zújar, } \\
\text { on the Eastern Side of the Province }\end{array}$ \\
\hline de Badajoz, hemos localizado & of Badajoz, we have located \\
\hline $\begin{array}{l}\text { un conjunto de } 58 \text { abrigos } \\
\text { con pinturas rupestres }\end{array}$ & $\begin{array}{l}\text { a group of } 58 \text { shelters } \\
\text { with schematic paintings. }\end{array}$ \\
\hline $\begin{array}{r}\text { esquemáticas. Presentan un } \\
\text { total de } 4.910 \text { figuras. }\end{array}$ & $\begin{array}{l}\text { Which contain a } \\
\text { total of } 4910 \text { figures. }\end{array}$ \\
\hline Su distribución espacial & Its spacial distribution has \\
\hline $\begin{array}{l}\text { ha permitido su agrupación } \\
\text { en tres núcleos diferentes: }\end{array}$ & $\begin{array}{l}\text { permitted us its agrupation } \\
\text { into three different nucleus: }\end{array}$ \\
\hline $\begin{array}{r}\text { Peñalsordo, Cabeza del Buey } \\
\text { y Helechal. }\end{array}$ & $\begin{array}{l}\text { Peñalsordo, Cabeza del Buey } \\
\text { and Helechal. }\end{array}$ \\
\hline
\end{tabular}

En la zona oriental de la provincia de Badajoz se localizan una serie de abrigos y covachos pintados con arte esquemático cuya distribución espacial nos ha permitido su agrupación en tres núcleos (Fig. 1): el núcleo de Peñalsordo, con 22 yacimientos rupestres y 2.344 figuras pintadas, el de Cabeza del Buey, con 11 y 1.347 figuras, y el de Helechal, con 25 yacimientos y 1.219 representaciones. Son en total 58 abrigos y 4.910 motivos pintados. La mayor parte de ellos permanecían inéditos hasta nuestros trabajos (Martínez Perelló, 1988-89; 1993a; 1993b; 1994; 1995; 1997;

* Doctora en Prehistoria por la UNED, e-mail: MabelMP@inicia.es. 
1999). Observamos que siendo el núcleo de Helechal el que más abrigos presenta no es el que posee mayor número de pinturas. Es el de Peñalsordo el que tiene más figuras en sus abrigos. $Y$ esto es debido a que en este núcleo se encuentran los 3 conjuntos más importantes de la zona por la cantidad y variedad de sus figuras: los 10 abrigos de Los Buitres, con 1.326 esquemas pictóricos, la Cueva del Bercialejo, con 675 representaciones y los 4 abrigos del Peñón del Pez, con 398 motivos.

Todos ellos se localizan en el entorno inmediato del Valle del Zújar. Se trata de la zona oriental de la comarca de La Serena, al sudeste de la provincia de Badajoz, área natural de paso de las llanuras cordobesas a la penillanura extremeña a través del valle del Zújar y de las vaguadas y puertos que interrumpen la cadena montañosa que se extiende en ese punto (Fig. 2). Estas sierras fueron prospectadas por primera vez por el abate Breuil entre 1915 y 1917. En 1933 fueron publicados por Breuil en el segundo volumen de su gran corpus sobre la pintura rupestre esquemática en la Península Ibérica, una serie de abrigos de gran interés que presentan sobre sus paredes abundantes manifestaciones pictóricas de tipo esquemático (Breuil, 1933). No se había realizado desde entonces una revisión de su trabajo ni de la sierra en busca de nuevos emplazamientos, por lo que el trabajo que aquí presentamos se hacía ya necesario. De los 58 abrigos que hemos estudiado, 35 han sido nuevos descubrimientos nuestros y de la mayoria restante se ignoraba hasta el momento su localización y su estado de conservación.

Nuestros objetivos al abordar este trabajo fueron los siguientes: realizar un completo corpus de las pinturas que incluyera las nuevas aportaciones y las modificaciones efectuadas al trabajo de Breuil, que han sido muchas. Efectuar tipologías y análisis estadísticos y técnicos que nos permitieran posteriormente establecer paralelos y rastrear influencias $y$ pervivencias. Aproximarnos a sus posibles significados para poder acercarnos a la mentalidad de los artistas. Establecer hipotéticas cronologías y contextualizar culturalmente a sus autores. Y finalmente conocer el estado de conservación de las pinturas y su necesidad de protección. Todo ello ha constituido nuestra Tesis Doctoral (Martínez Perelló, 1999). De todo este extenso trabajo presentamos en el presente artículo un breve resumen en el que se tratan algunos aspectos significativos.

\section{LOCALIZACIÓN}

En primer lugar conviene resaltar que las pinturas se localizan tanto al aire libre como en abrigos y covachos poco profundos constituidos por 


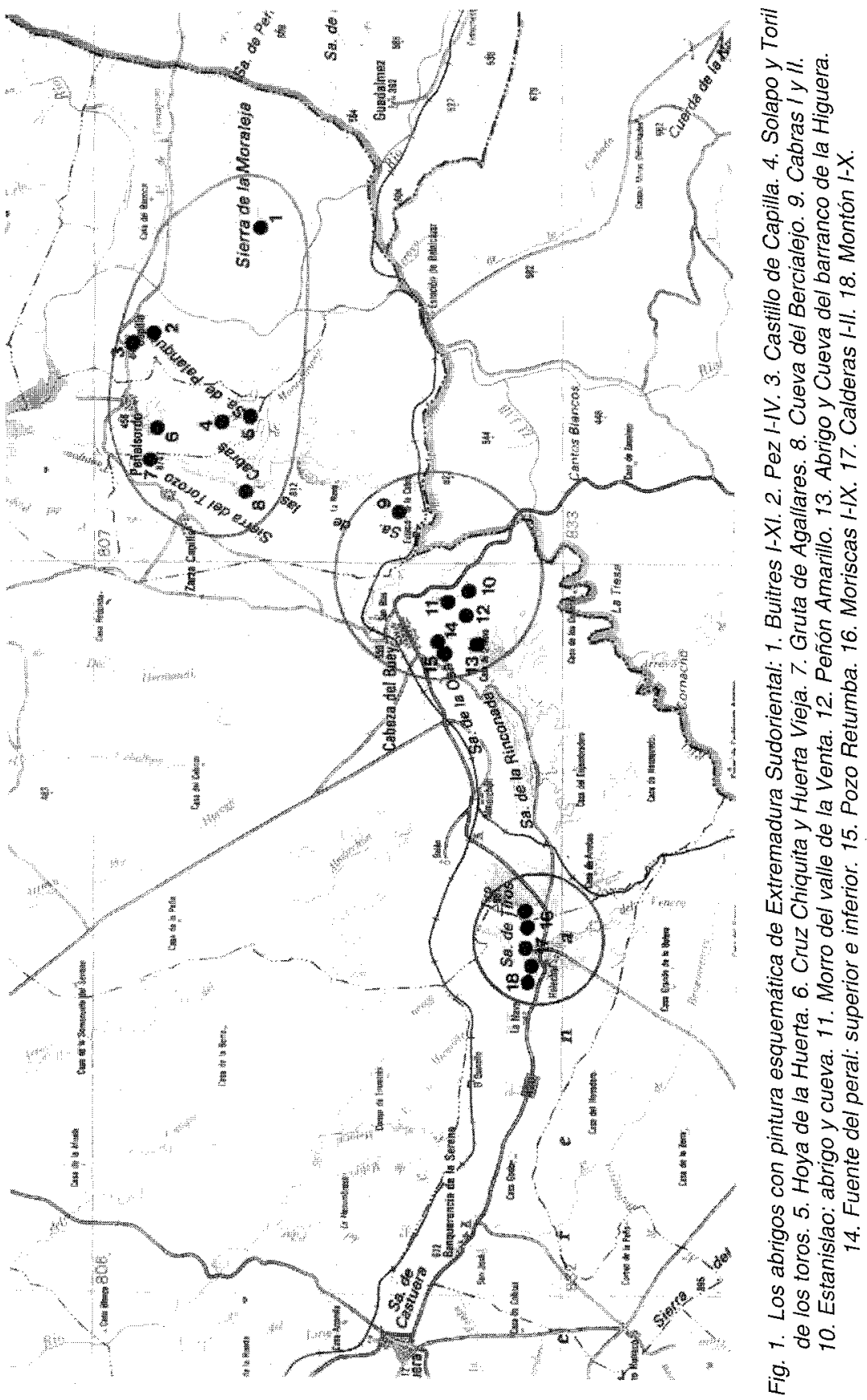




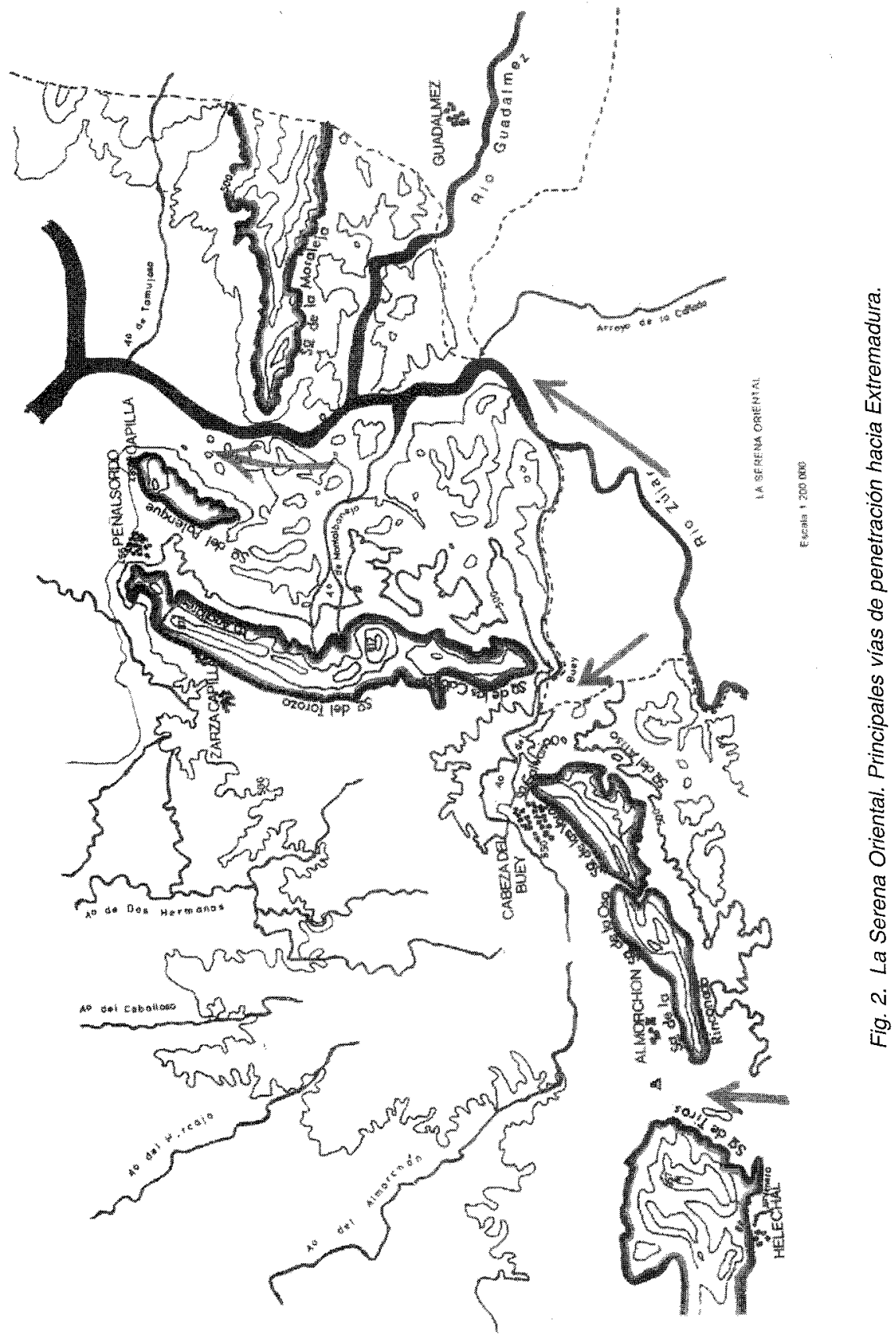


cuarcitas ordovícicas y silúricas, muchas de ellas de disposición subvertical (Fig. 3), y situados a una altitud que oscila entre 600 y $800 \mathrm{~m}$, teniendo en cuenta que las sierras son de poca altura. Se trata de la zona de contacto entre la ladera y la cresta de las sierras, elevaciones que forman parte de la cadena que recorre la provincia de Badajoz por su extremo oriental. Es una zona, por lo tanto, con características apropiadas para el pastoreo de ganado caprino, ovino y porcino. Es un paisaje de monte bajo, arbolado de robles, encinas, alcornoques, quejigos y jaras, con dehesas de montanera, y algunos cultivos de secano. Tanto el río Zújar como sus arroyos permiten la existencia de pequeñas huertas. Estudios recientes de arqueozoología y arqueobotánica realizados en algunos lugares de la provincia de Badajoz demuestran que este paisaje y su aprovechamiento económico debió ser similar en la protohistoria (Castaños Ugarte, 1991; Rodriguez Díaz, 1998; Pavón, 1994).

La mayoría de los abrigos se encuentran en lugares prominentes y con amplia visibilidad, dominando grandes extensiones de terreno y especialmente zonas de paso entre montañas o vías de comunicación naturales. Otra característica común es su proximidad a cursos de agua, como ríos, arroyos o simples manantiales. Aunque desconocemos el trazado de los caminos prehistóricos es innegable que debieron existir ciertos puntos

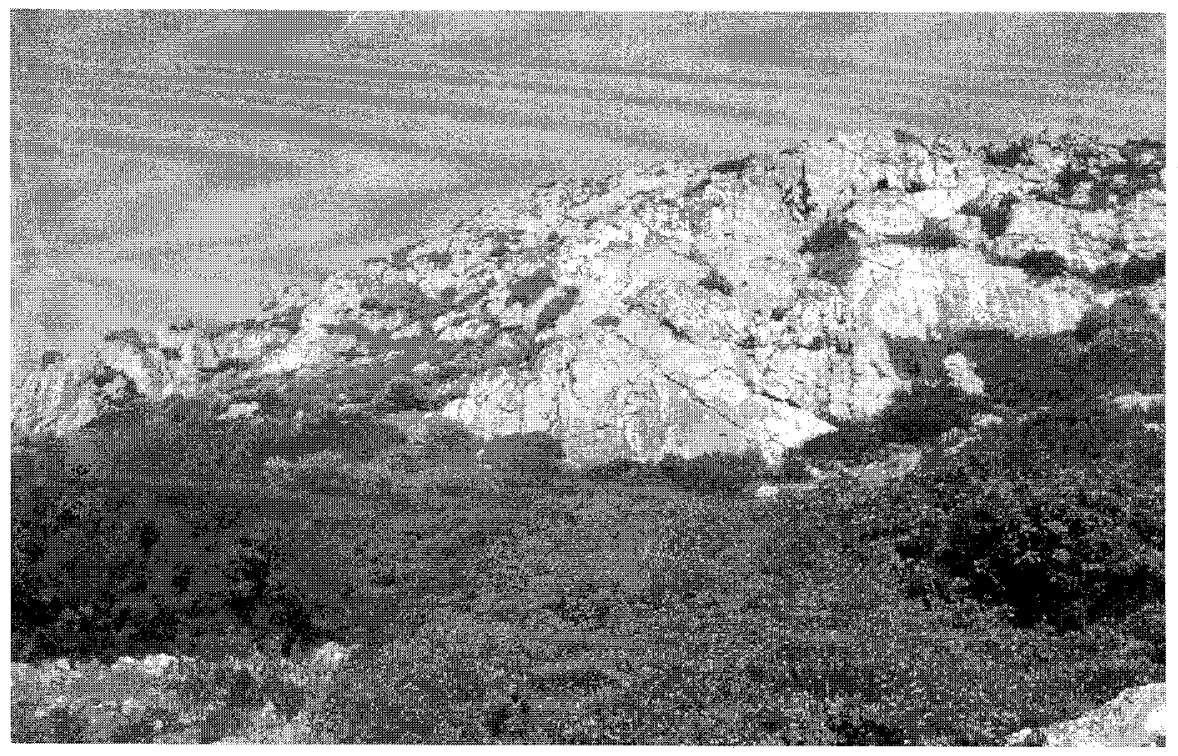

Fig. 3. Las cuarcitas silúricas de las sierras de Extremadura Sudoriental. Los abrigos de Puerto Alonzo. 
obligados de paso determinados por las características orográficas, puntos en los que hemos constatado una mayor concentración de estaciones rupestres. Esta ubicación puede darnos la clave para intentar aproximarnos al significado de estas pinturas, o al menos al de algunas de ellas.

En ciertas ocasiones estos abrigos hoy en día son lugares elegidos como refugio por los pastores, y probablemente lo fueron también en la prehistoria.

Sin embargo, existen otros casos en los que no parece haber sido el refugio el motivo de su ocupación. Esto es así en las oquedades rocosas de pequeñas dimensiones o casi inaccesibles. Tal vez su elección como soporte pictórico se deba más a su localización o a las características físicas del abrigo.

Para la realización de las pinturas hemos constatado cómo no se han aprovechado todas las paredes del abrigo que aparentemente parecen disponibles y apropiadas. Realmente son escasas las pinturas que ocupan la totalidad del abrigo o la mayor parte de él y muchas veces se pintan paredes irregulares y se desprecian otras lisas. Esto nos lleva a pensar en la probable existencia de una selección previa tanto de los abrigos como de las paredes que iban a ser pintadas. Estos criterios de selección podrían tener en cuenta que las pinturas pudieran ser facilmente observables por los espectadores, que tuvieran mayores posibilidades de conservación, que se adaptaran a un "programa iconográfico" preestablecido, que existiera en el abrigo un ambiente de recogimiento, una amplia visibilidad y control sobre el paisaje circundante, etc. Además observamos como con cierta frecuencia alrededor de un yacimiento importante por la cantidad y la variedad de sus motivos se localizan otras estaciones rupestres de menor relevancia con las que suele tener contacto visual. Como ocurre, por citar dos ejemplos, con los abrigos del Cerro Estanislao ó desde los que se divisan los del Valle del Aliso y del Morro del Valle de la Venta. Igual sucede con los abrigos del Peñón del Pez y con los de la Sierra de Los Buitres.

\section{ESTILO}

En lo que se refiere a las cuestiones estilísticas, todas estas manifestaciones artísticas, en general, están pintadas reduciendo sus rasgos a los trazos más elementales lo que dificulta enormemente su interpretación. En algunas ocasiones el dibujo de detalles anatómicos, de vestimenta, adornos, etc., nos permite identificar la figura. Tenemos que señalar 
que muchas de las interpretaciones que hemos efetuado son muy diferentes de las realizadas en su día por el abate Breuil.

Tradicionalmente se habían considerado las pinturas esquemáticas como figuraciones aisladas, sin formar escenas ni composiciones, y carentes de dinamismo y de perspectiva. Sin embargo, el estudio detallado de los paneles ha permitido, en primer lugar, observar asociaciones entre las figuras e identificar escenas y complejas composiciones. Además hemos apreciado cierto dinamismo y el empleo de la perspectiva en algunos motivos, como son el recurso de multiplicar las patas en las figuras interpretadas como cuadrúpedos para indicar el movimiento o la existencia de ganado, el alzado de los brazos en las figuras antropomorfas bitriangulares dotándolas de dinamismo, y la disposción piramidal de algunos conjuntos de motivos quizá para reflejar una determinada organización social (Fig. 4).

Sin embargo, todo esto es relativamente escaso si comparamos con el elevado volumen de figuras absolutamente hieráticas y abstractas que contienen los paneles pintados de esta zona.

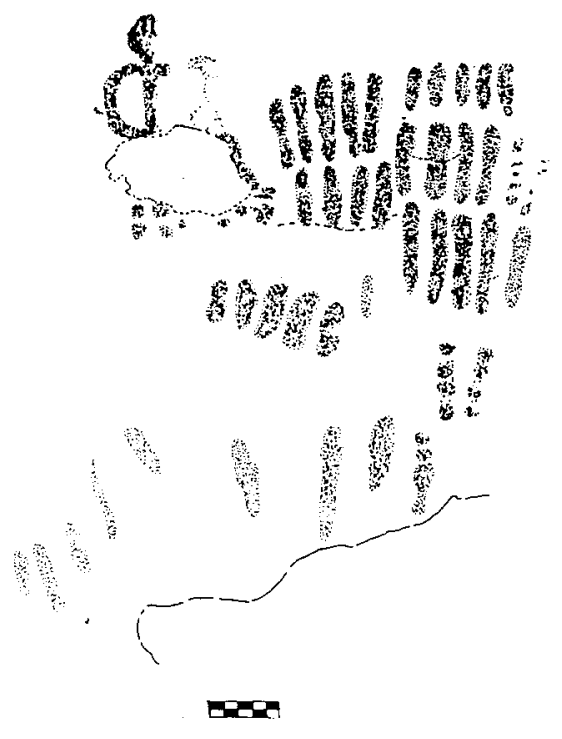

MORISCAS I P-5

Fig. 4. Abrigo Moriscas 1, panel 5.

Motivo antropomorfo en "hi» dominando un grupo de barras interpretadas como figuras humanas. 


\section{TÉCNICA}

Técnicamente se han empleado en su elaboración la tinta plana y la técnica lineal, combinándose en algunos casos ambas en el mismo motivo.

Por otra parte el tamaño de las figuras y la anchura de los trazos son los comunes en la mayoría de manifestaciones rupestres de este tipo localizadas a lo largo y ancho de la Península Ibérica.

La coloración de estas pinturas es, en general, rojiza, con variaciones hacia tonos más oscuros y claros. Este colorante es elaborado gracias a la abundancia de vetas de hematites de hierro en la zona. El estudio detallado de las pinturas y de sus pigmentos nos ha permitido distinguir superposiciones y repintados, frecuentemente de colores más oscuros sobre otros más claros, aunque también se produce lo contrario.

Existen muy pocos motivos realizados en blanco, o tal vez nos pasen desapercibidos debido a que con el paso del tiempo toman una tonalidad pajiza que los hace muy poco visibles.

El negro, obtenido quizá del carbón, es algo más utilizado que el blanco.

En lo que se refiere a la idea apuntada por algunos autores sobre la preparación previa de las superficies sobre las que se pinta (Sánchez Gómez,1983:152; Ortiz y Muñoz-Torrero,1995), tras la observación directa y detenida de los paneles no creemos que, al menos en los abrigos que hemos estudiado, ésto se haya producido.

Finalmente hemos de señalar la utilización, en ciertas ocasiones, de determinados elementos del relieve rocoso - como grietas, descamaciones de la corteza rocosa, abultamientos o rehundimientos de la pared...para conformar figuras o incluso escenas, dotándolas en ocasiones de un sentido especial al quedar de esta manera enmarcadas y destacadas del resto de las figuraciones.

\section{TIPOS}

El estudio tipológico y temático proporciona una mayoría de representaciones de las figuras tipo barra, que se concentran en el núcleo de Cabeza del Buey y suponen el $51,2 \%$ del total de las pinturas, y del tipo punto, que suponen un $26,3 \%$ del total y se concentran en Peñalsordo. Estos tipos suelen aparecer formando conjuntos.

Les siguen en cantidad las figuras humanas (Fig. 5) y los motivos de tipo ramiforme (Fig. 6), que según los casos se pueden interpretar como 
antropomorfos (Breuil y Burkitt, 1929:8), formas vegetales e incluso como cornamentas de cérvidos (Acosta, 1968:124 y 126, lám. 36). Suponen el $6,9 \%$ y el $2,7 \%$ del total y se distribuyen por igual en los tres núcleos en el caso de las figuras humanas, mientras que los ramiformes predominan en Helechal.

Otros esquemas, como los pectiniformes, algunos motivos en «pi» griega y los serpentiformes, los interpretamos en muchas ocasiones como figuras animales, y alcanzan el $1,4 \%$ en el caso de los pectiniformes (Fig. 7), que predominan en Peñalsordo, y el $0,1 \%$ en los otros dos casos, con una concentración en el núcleo de Helechal.

Tras las figuras humanas y animales les siguen en orden cuantitativo los petroglifoides, líneas en zig zag y onduladas, estructuras y escaleriformes. Los soliformes y esteliformes, figuras en $U$ y en «pi» griega invertida, en « $V\rangle$, carros, trineos o narrias, idoliformes y armas están representados, aunque escasamente, en el conjunto de los abrigos. Es significativa su especial concentración en determinadas estaciones rupestres: estructuras y

ANTROPOMORFOS I

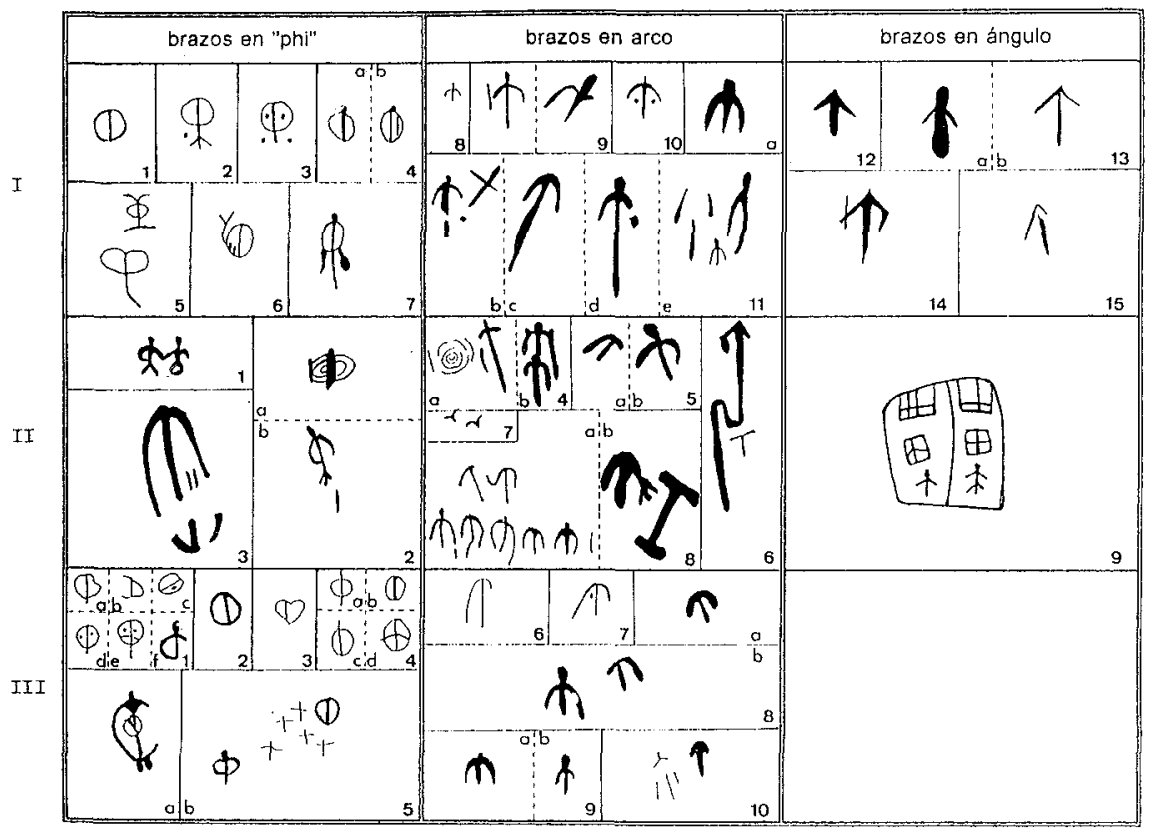

Fig. 5. Algunos de los subtipos del tipo antropomorto, hallados en los núcleos de: I. Peñalsordo, II. Cabeza del Buey, III. Helechal. 


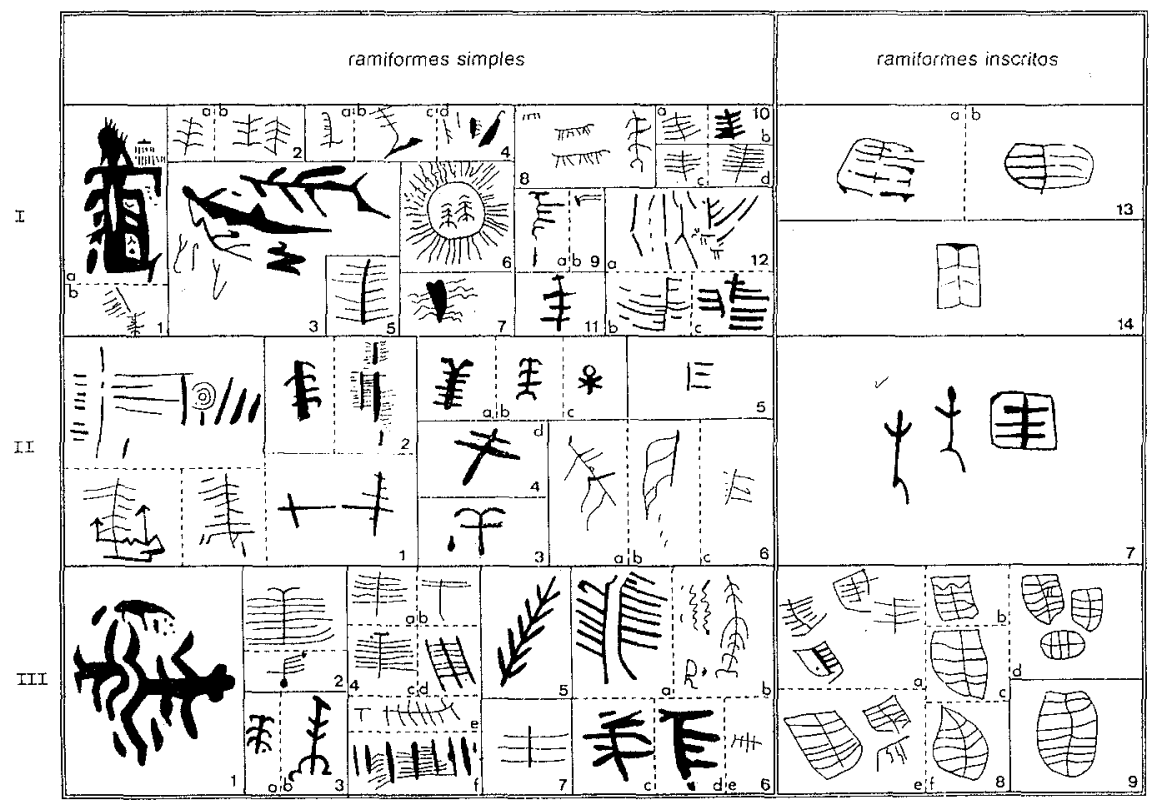

Fig. 6. Tipo ramiforme en los núcleos de: I. Peñalsordo, II. Cabeza del Buey, III. Helechal.

PECTINIFORME

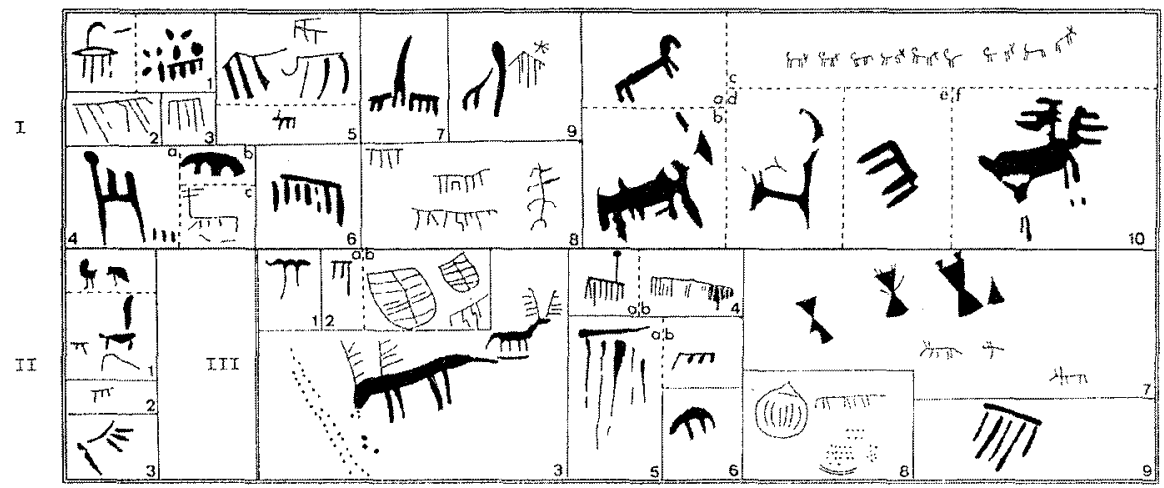

Fig. 7. Tipo pectiniforme: I. Núcleo de Peñalsordo, II. Núcleo de Cabeza del Buey, III. Núcleo de Helechal.

escaleriformes, carros y trineos o narrias se pintan con profusión en los abrigos de Los Buitres. La abundancia de representaciones de estos tipos 
es característica de los abrigos de esta zona, lo que los diferencia del resto de la pintura esquemática pacense y peninsular (Figs. 8 y 9).

A pesar del mal estado de conservación en que se encuentran la mayoría de las pinturas, del estado fragmentario de los paneles y de la ab-

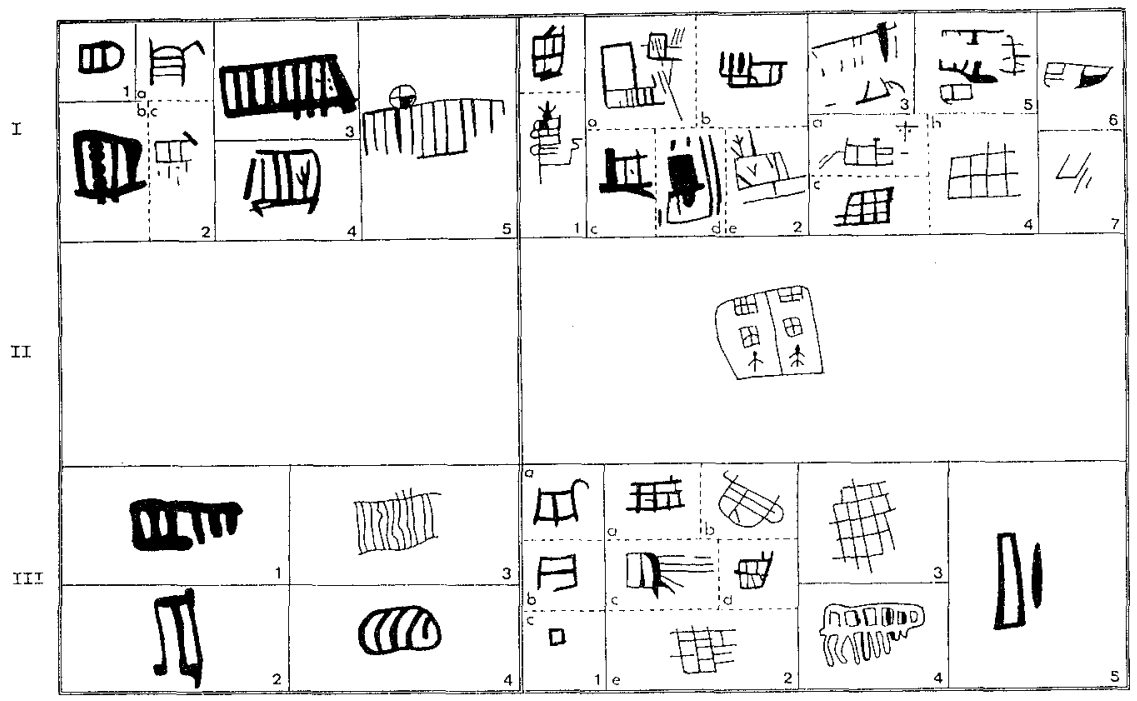

Fig. 8. Tipos escaleriforme y estructura en los núcleos de: I. Peñalsordo, II. Cabeza del Buey, III. Helechal.

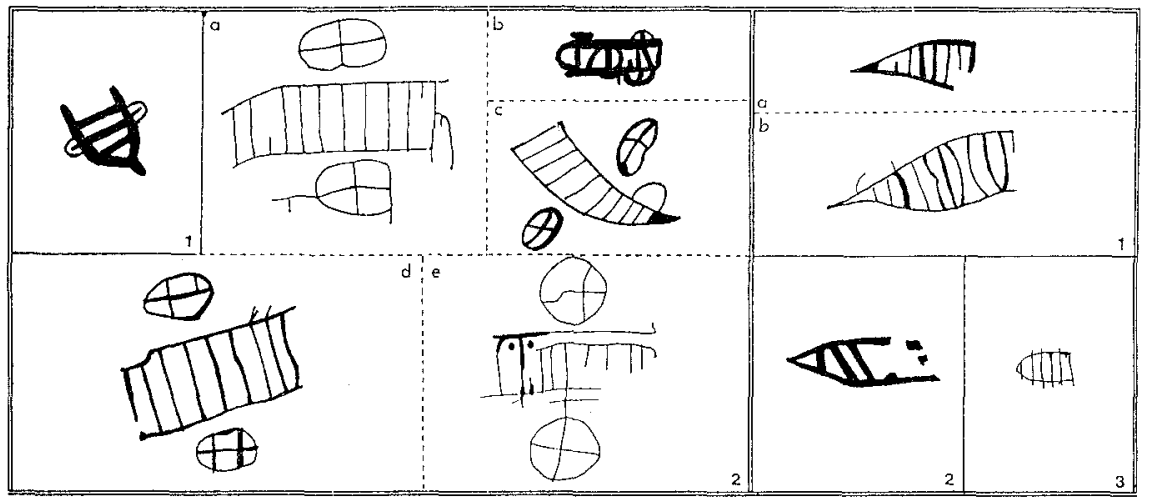

Fig. 9. Tipo carro y trineo: I. Núcleo de Peñalsordo, II. Núcleo de Helechal. 
soluta esquematización y abstracción de los motivos y conjuntos, es posible determinar la representación de algunas actividades que parecen ser sociales, rituales y económicas, que nos aportan algunos indicios de cómo debió ser la sociedad que produjo tales obras de arte.

Ciertas representaciones parecen hablarnos de temas trascendentales, como prácticas y ceremonias rituales, quizá un culto a ciertas divinidades... (Fig. 10), pero también muchas de las figuras reflejan actividades de la vida cotidiana, como el trabajo de la tierra, el pastoreo, la caza, etc. quizá con un objetivo más narrativo (Fig. 11).

Además, son muchos los motivos que no reproducen objetos o situaciones reales, sino que son signos y símbolos abstractos elaborados mentalmente por sus creadores, por lo que nos resulta imposible llegar a conocer su significado (Grande del Brío y Gonzalez-Tablas, '1983:193-194).

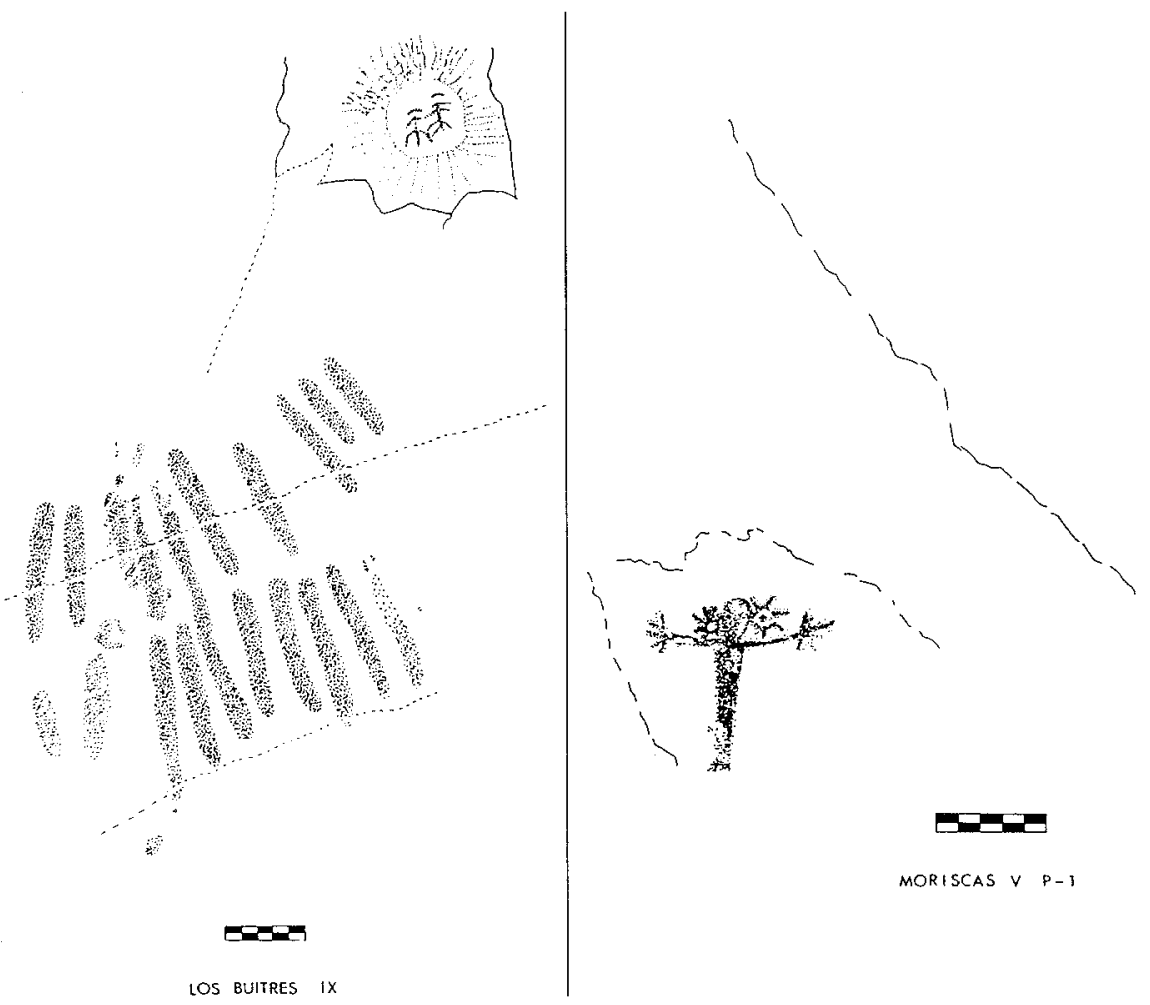

Fig. 10. Los Buitres IX y Moriscas V, panel 1. Soliforme con antropomorfos dominando un grupo de barras y figura antropomorfa oculada y oferente. 

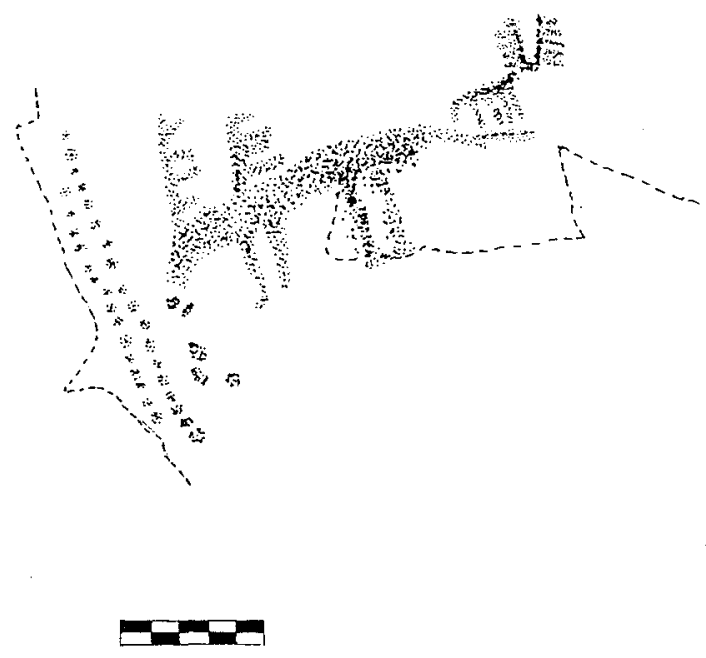

MORISCAS IV P-I

Fig. 11. Moriscas IV, panel 1. Ciervo herido, sangrando por la boca, ante su propio rostro.

Tanto su morfología como sus asociaciones responderían a un código en el que dependiendo del orden de los grafismos se querrian expresar conceptos diferentes. Esto nos llevaría a hablar de un sistema de escritura ideográfica incipiente (Acosta, 1968:188;1984:31-61; Almagro Basch, 1947:94-99; Beltrán, 1989:116-118; Nieto, 1985:493; Ripoll, 1968:165-192; 1983:27-35).

\section{SIGNIFICADO}

En lo que se refiere al significado de estas pinturas, es interesante la idea expuesta por algunos investigadores que proponen que las pinturas rupestres serían una señalización de la presencia de buenos pastizales en el valle, y pondrían además los ganados bajo la protección de un ser superior (Nieto, 1983). Quizá podríamos aplicar esta explicación a algunos de nuestros abrigos. Pero creemos que no se pueden desechar las teorías defendidas por otros especialistas de un cierto carácter ritual, mágico, quizá «religioso»... de los lugares (Cabré, 1941:344; Hernández-Pacheco, 1918; Jordá, 1983; Kühn, 1957:128-129; Ripoll, 1968:188).

Nosotros aunamos ambas interpretaciones y creemos que los autores de las pinturas pudieron ser grupos de pastores que las utilizaron como 
puntos de referencia en sus desplazamientos y como señales en el paisaje, lo que proporcionaría información sobre la identidad distintiva de quienes las realizaron, empleándose también los abrigos, aunque no siempre los mismos, como centros de prácticas rituales. Este modo de comunicarse es propio de grupos en zonas limítrofes (Bradley, 1991:77-80), donde se contacta con otros grupos extraños, como ciertamente es limítrofe el Valle del Zújar y, en general, toda la Siberia extremeña en la que se integra este valle. Esta es, en efecto, una zona de paisaje montuoso cuya explotación sólo es posible en los lugares más llanos y accesibles, poco poblada y de gran importancia estratégica ya que al este limita con el Valle de Alcudia y sus excelentes pastos y con la zona de Almadén de gran riqueza minera, y al oeste limita con la comarca de la Serena, de productivas dehesas, como parece que pudo ser también en la prehistoria y protohistoria (Rodriguez Díaz, 1998). Por ello, es una zona propicia para la aparición de límites entre áreas más ricas; y resulta muy significativo como en esta zona de contacto natural confluyen, además, en la actualidad, tres provincias de tres regiones y comunidades autónomas diferentes: Ciudad Real, Córdoba y Badajoz.

Es en este espacio limítrofe, indudablemente, donde mayor importancia adquiere la necesidad de remarcar la pertenencia a un grupo determinado, sobre todo en los que poseen una economía movil como la propia de los pastos, y es donde existe, además mayor posibilidad de conflictos, por lo que las representaciones rupestres desempeñararían un importante papel corino signos de identidad tribal, al igual que lo harán durante el Bronce Final las estelas (Galán, 1994; Galán y Martín, 1991-92), que curiosamente tendrán en la zona del Valle del Zújar una especial concentración.

\section{CONTEXTO ARQUEOLÓGICO}

En las cercanías de algunos abrigos pintados se han localizado algunos materiales arqueológicos de gran interés que, unidos a los yacimientos arqueológicos ya conocidos y a los hallados en nuestras prospecciones, nos ofrecen un marco cronológico-cultural que, con las debidas reservas puesto que no podemos asegurar con total certeza la coetaneidad de estos restos con las pinturas, consideramos válido para poder encuadrar nuestras manifestaciones rupestres. $Y$ esto es debido a que son los únicos vestigios humanos localizados en la zona, aparte de las pinturas, y cronológicamente se sitúan en un momento que corresponde al que tradicionalmente se ha tomado como el del desarrollo del arte rupestre esquemático peninsular, que va desde el Neolítico Final hasta las postrimerías de la Edad del Bronce e inicios de la del Hierro. 
El Valle del Zújar: un importante enclave para el arte rupestre esquemático...

Así, las crestas de Los Buitres y sus abrigos, algunos con impresionantes dibujos esquemáticos de carros, dominan la Dehesa de la Piedra Santa, lugar en el que el río Guadalmez va a desaguar en el Zújar (Fig. 12). En ese punto, vía natural importante, (ver Fig. 2), se han hallado diez estelas grabadas del Bronce Final, algunas de ellas también con representaciones de carros (Fig. 13).

Sin embargo, estos carros de las estelas difieren en algunos aspectos de los carros pintados: se representan los animales de tiro, son carros ligeros poco aptos para el terreno agreste de esta zona, y creemos que no son un referente real sino que copian un modelo de lo que es un bien de prestigio en ese momento, para subrrayar el estatus privilegiado de las élites que lo representan en sus estelas y marcar con ellas sus dominios (Galán, 1994:80-81).

Los carros de Los Buitres, por el contrario, son carros pesados de transporte, no se representa el tiro, y que son el reflejo más real de los vehículos que pudieron emplearse en esta zona (Fig. 14). Sin embargo creemos que fueron pintados con el mismo sentido de marcadores territoriales que los de las estelas, aparte del posible significado ritual, funerario, etc. que se les pueda suponer a ambas manifestaciones. Su cronología podría ser la misma: Bronce Final-principios de la Edad del Hierro (Almagro Gorbea, 1977:185; Iglesias, 1980:192; Bueno et alii, 1984:479; Vaquerizo, 1985:466; Fernández-Miranda y Olmos, 1986:105-107 y 152).

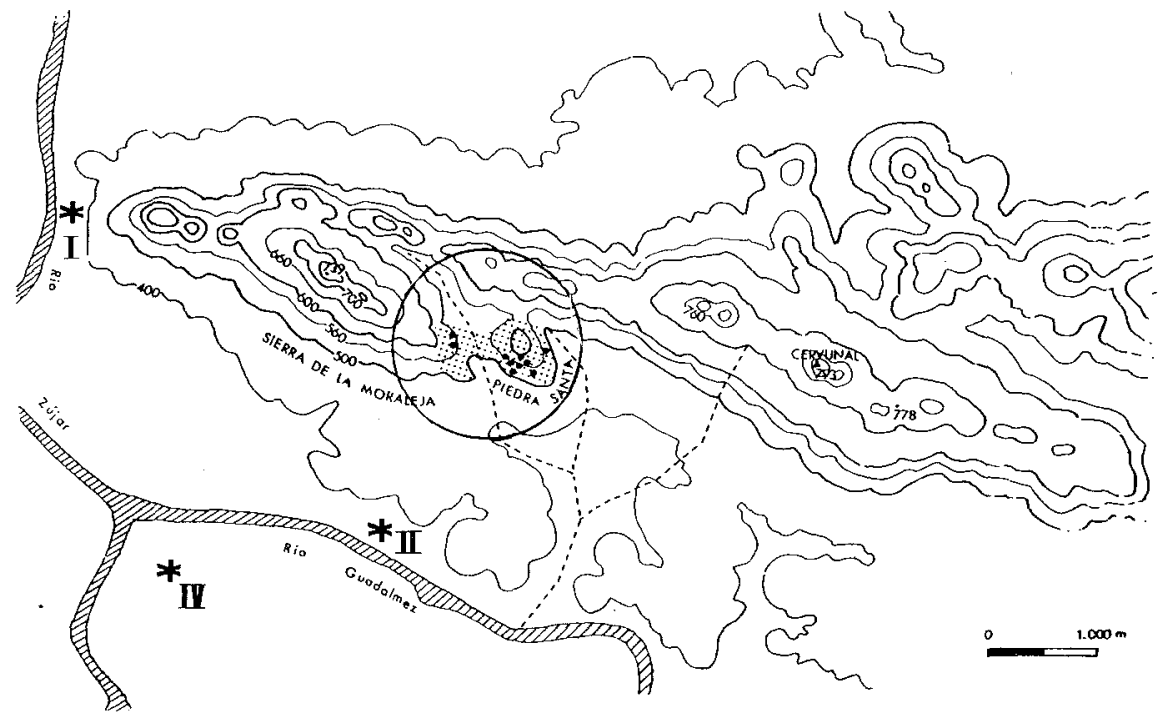

Fig. 12. Situaciónde los abrigos de Los Buitres y de las estelas de Capilla I, II y IV. 


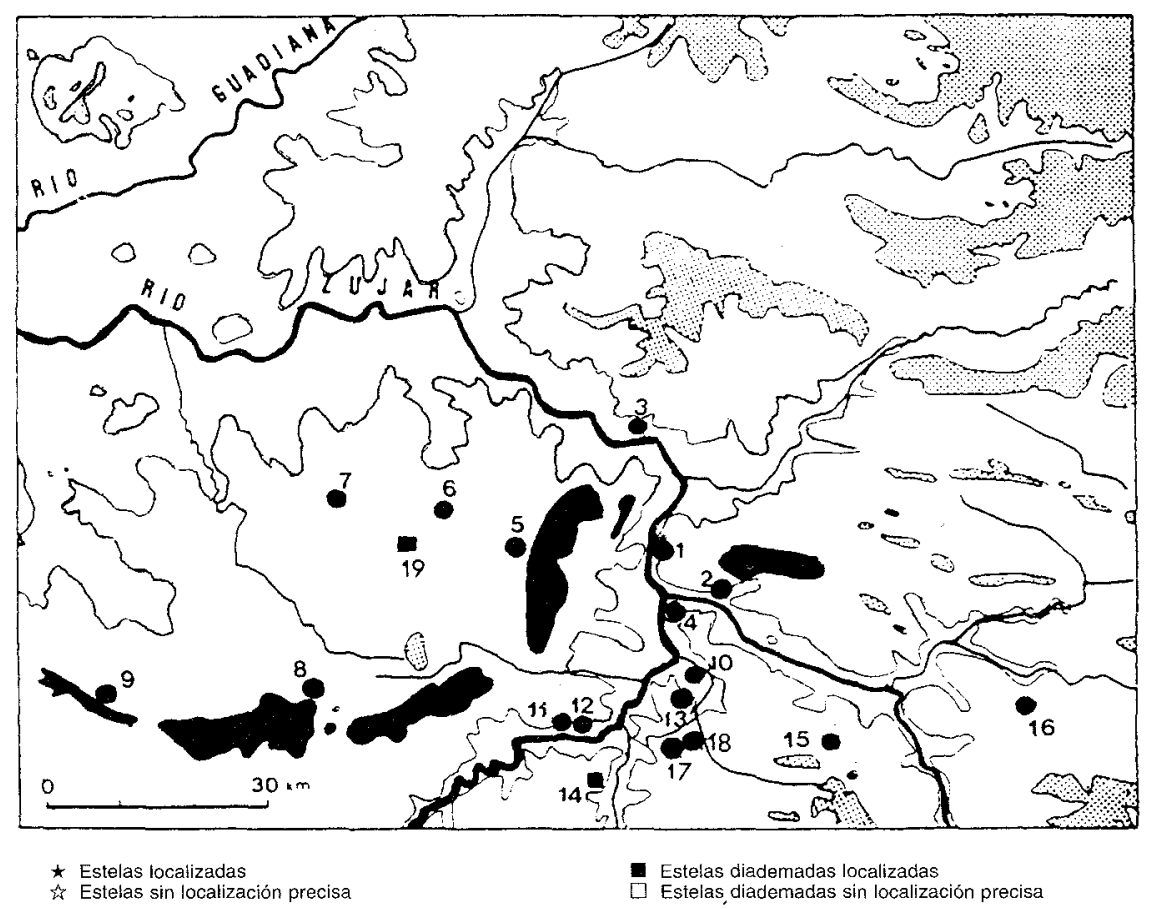

Fig. 13. Concentración de estelas en torno al rio Zújar (basado en Galán, 1994:40): 1. Capilla I. 2. Capilla II. 3. Capilla III. 4. Capilla IV. 5. Zarza Capilla. 6. Cabeza del Buey I. 7. Cabeza del Buey II. 8. Cabeza del Buey III. 9. Berquerencia. 10. Viso I. 11. Viso II. 12. Viso III. 13. Viso IV. 14. Belalcázar. 15. La Berfilla. 16. Alamillo. 17. Viso V. 18. Viso VI. 19. Valle del Zújar.

Sierras con pinturas rupestres esquemáticas.

Muy cerca de los mencionados abrigos de Los Buitres se localizan los abrigos del Peñón del Pez, que controlan igualmente el valle del Zújar y la penillanura de La Serena. Se sitúan en el mismo cerro sobre cuya cima se ubica un importante castro que parece remontarse al Bronce Final (Vaquerizo, 1986:10-18; Enríquez y Jiménez, 1989:146; Rodríguez, 1989:165-224 y 1995:104; Pastor et alii, 1992; Pavón, 1995:53). Muy próximo a él encontramos la representación pictórica esquemática de un guerrero tocado con cuernos (Fig. 15), que por similitud con los representados en las estelas del Bronce Final-inicios del Hierro (Almagro Basch, 1966:122-124 y 178-180), podría indicarnos para esta pintura una cronología en torno a esta época.

Otros abrigos pintados (Hoya de la Huerta, Cueva y Solapo del Toril de los Toros y Cabras I y II), se encuentran muy próximos a dos yacimientos, 


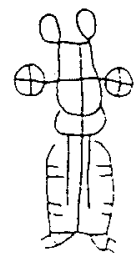

a

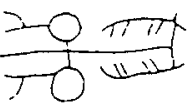

d

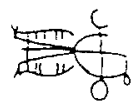

b

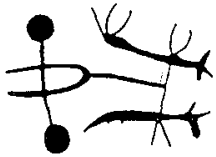

e

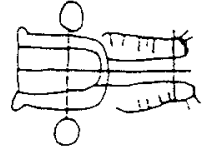

$\varsigma$
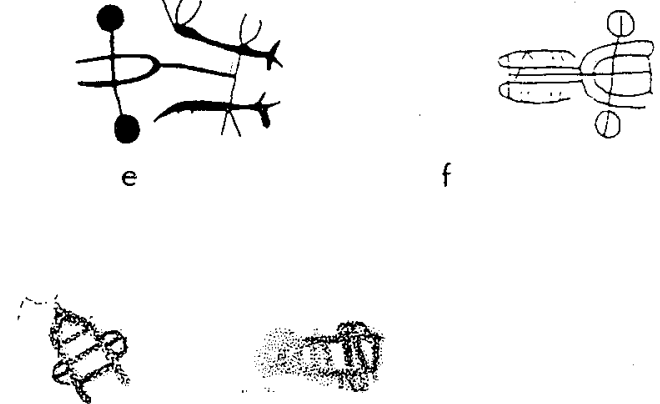

f
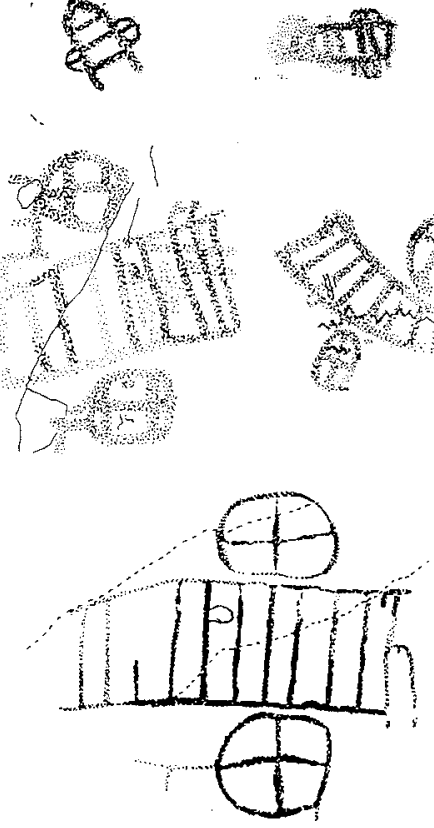

Fig. 14. Carros de estelas del Zújar («a» - «f»). Representaciones de Carros de Los Buitres. 


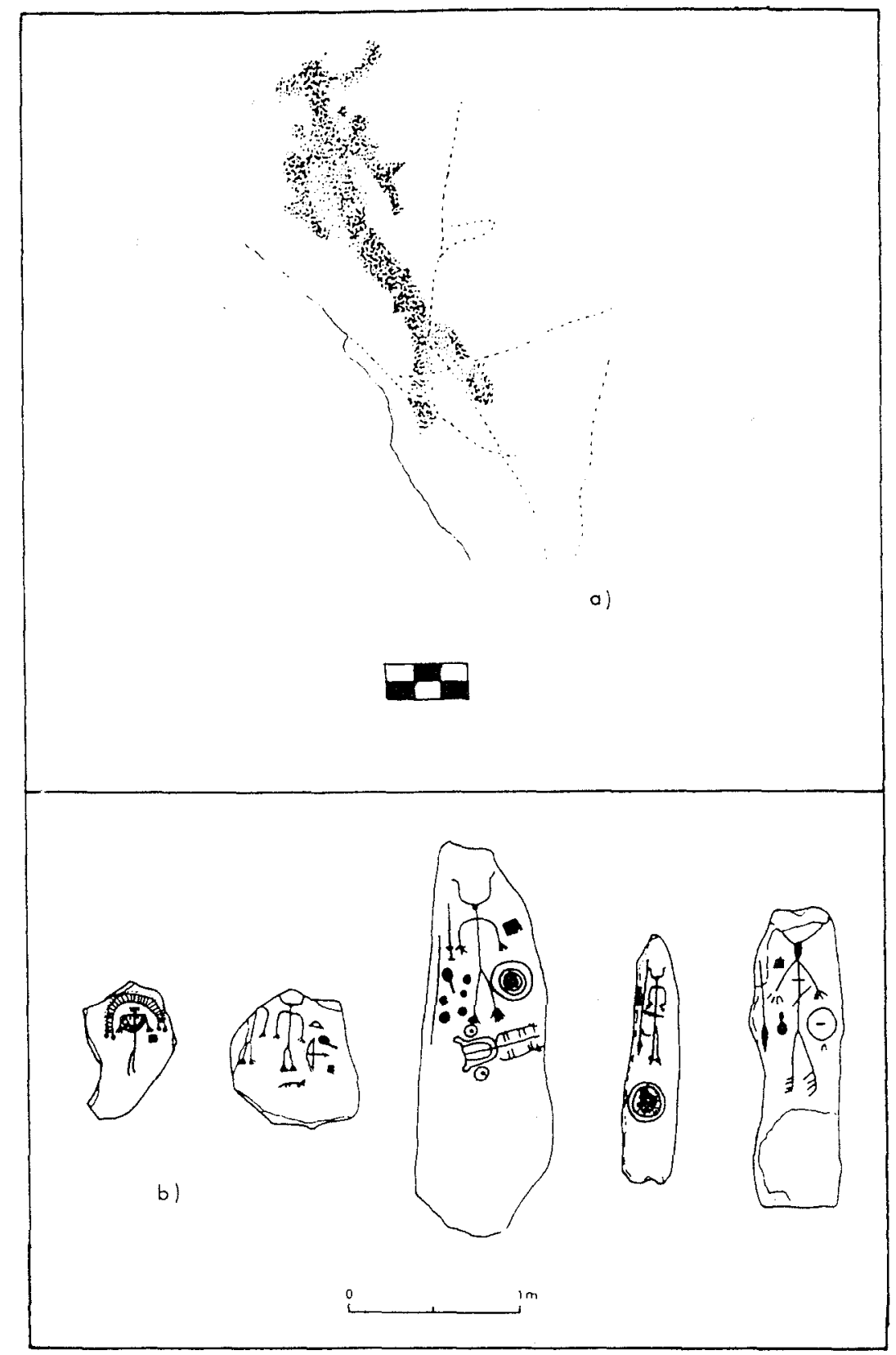

Fig. 15. a) Guerrero del Pez. b) Estelas de Capilla I, Capilla IV, Fuente de Cantos, Magacela y Esparragosa de Lares. 
Cabras y Posada de Gil, cuya cerámica e industria lítica nos permiten situarlos en un contexto del Neolítico Final-Calcolítico Pleno (Martínez Perelló, 1999) (Fig. 16). En las proximidades a estos abrigos se han localizado ocho estelas más del Bronce Final.

Y finalmente, el cerro El Montón, en el núcleo de Helechal, ha proporcionado además de trece abrigos pintados y doce más en sus proximidades (los conjuntos de Las Moriscas y Las Calderas), restos de un poblado sobre su cima cuya cerámica parece corresponder a un Bronce AntiguoPleno, aproximación cronológica realizada en base a materiales de superficie, por lo que se debe tomar con precaución (Martínez Perelló, 1995 y 1999). El hecho de que Helechal sea el núcleo que mayor número de abrigos presenta pero el que menor número de figuras pintadas posee, sin superposiciones ni repintados, nos hace pensar que estos abrigos de El Montón quizá debieron emplearse durante un periodo de tiempo no muy largo (¿tal vez contemporáneo a los restos del poblado?). En sus cercanías se hallaron dos estelas del Bronce Final así como el célebre carrito votivo de Almorchón (Blazquez, 1955-56:41-60), fechado en la segunda Edad del Hierro y reflejo ya de las perduraciones orientalizantes y los nuevos impulsos mediterráneos que llegarán a la zona.

\section{CONTEXTO CRONOLÓGICO-CULTURAL}

Tras el análisis artístico y arqueológico realizado hemos propuesto como hipótesis de trabajo una secuencia para la pintura rupestre esquemática de la zona oriental de la Comarca de la Serena (Fig. 17.1) que se iniciaría posiblemente en el Neolítico Final-Calcolítico, momento en el que se produjo el principal poblamiento de la provincia de Badajoz (Hurtado, 1995a y 1995b:53-80), y al que pertenecen algunos de los yacimientos que hemos localizado en las proximidades de los abrigos pintados (Fig. 17.2). Y aunque no poseemos paralelos muebles cercanos si existen en abundancia en otras zonas próximas, como en Andalucía Occidental y ya se encuentran paralelos en el arte megalítico, que iniciándose en el Neolítico se desarrollará en el occidente peninsular a lo largo del periodo Calcolítico. Es durante la Edad de Cobre cuando se produce el momento de auge y explendor del arte esquemático extremeño, apareciendo además nuevos temas como los oculados (Acosta, 1984: 31-61), tan representados en los ídolos muebles extremeños. Este arte pervive durante el Bronce Antiguo y Pleno, a pesar del aparente descenso de población que parece observarse en la provincia, para alcanzar el momento final de la Edad del Bronce y principios de la del Hierro (Fig. 17) (Fig. 17.3). En este momento tiene lugar en Extremadura un proceso de intercambios económicos, comerciales y artesanales, consolidándose las redes 

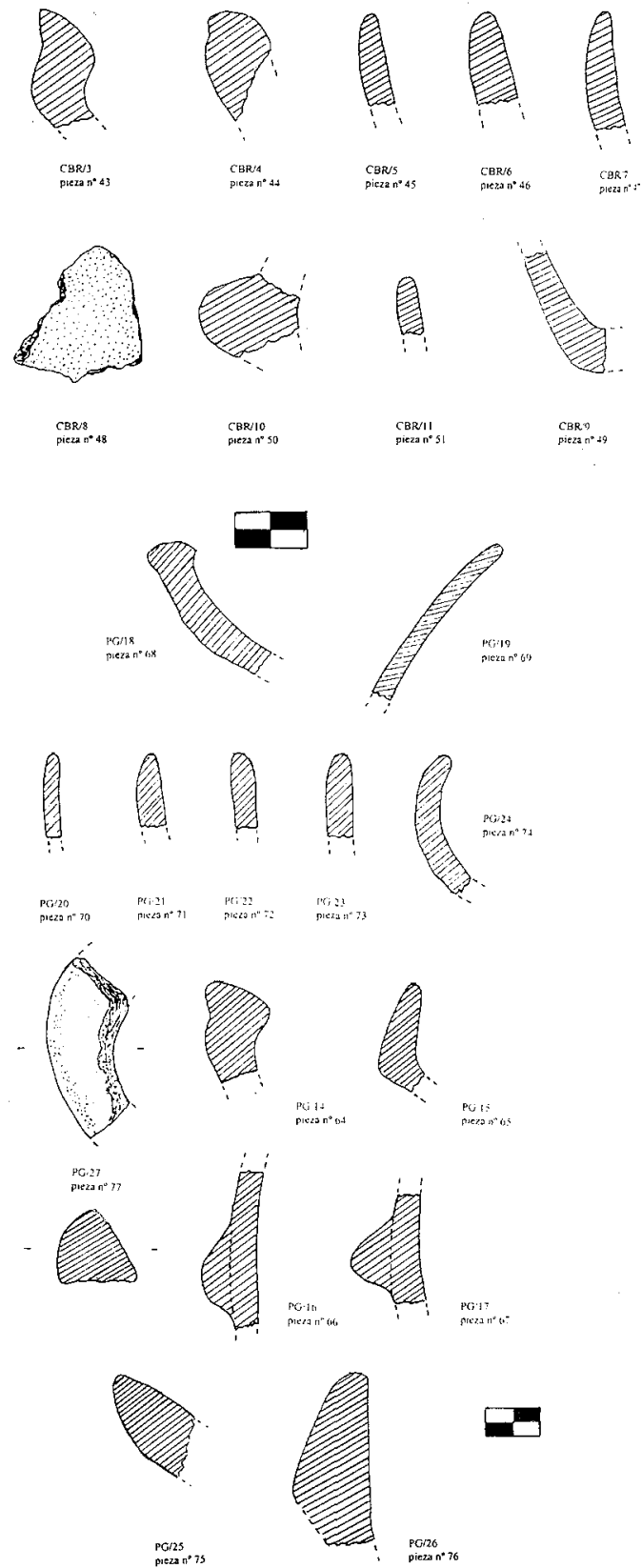

Fig. 16. Cerámica de Las Cabras y de Posada de Gil. 


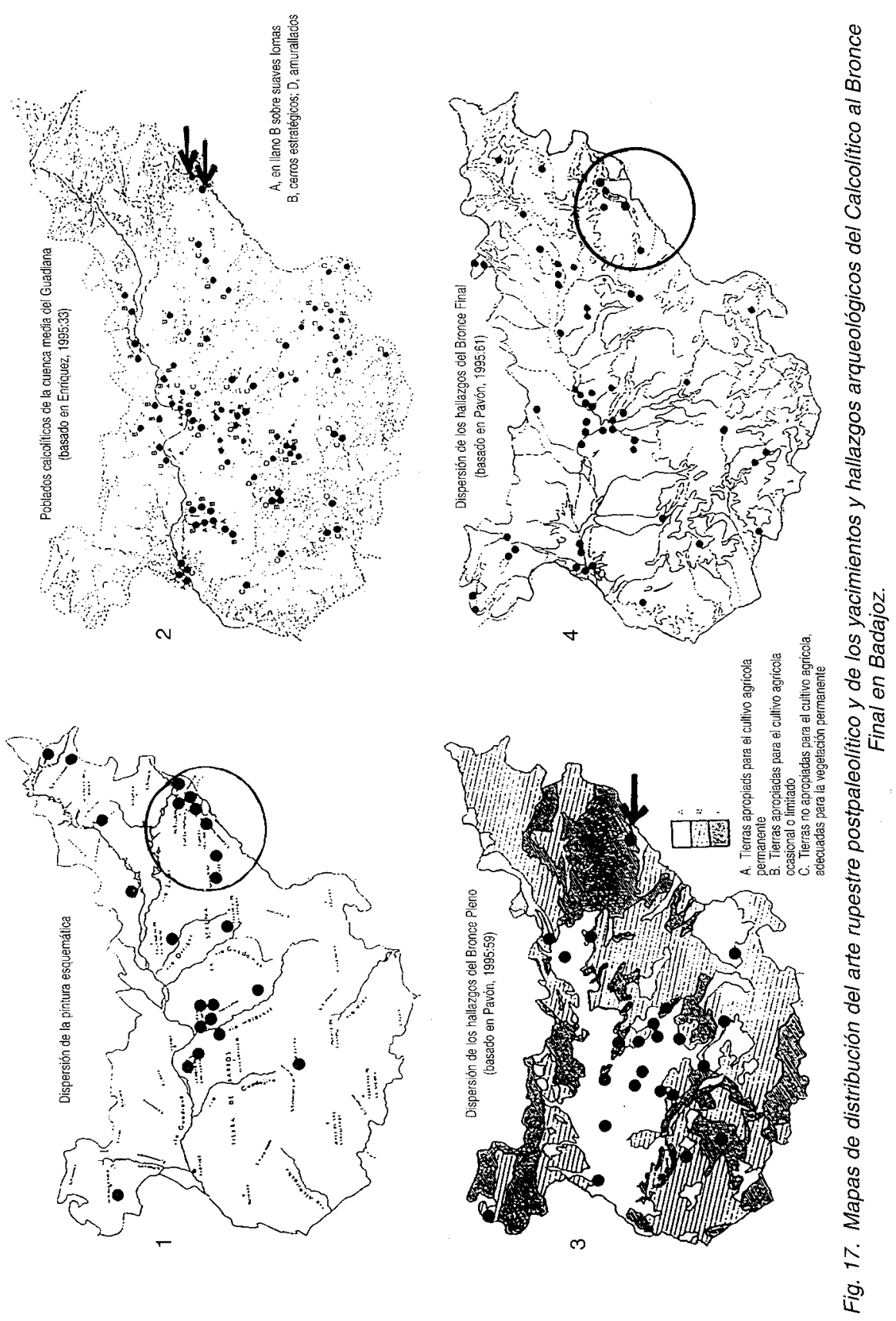


interregionales y llegándo a Extremadura una serie de elementos de prestigio que nos hablarán de la presencia de unas élites o grupos privilegiados dentro de la sociedad rural y pastoril del Bronce extremeño (Ruiz-Gálvez, 1986, 1987, 1988, 1989, 1990, 1991, 1992 y 1993) (Fig. 17.4). Estos elementos de prestigio quedarán reflejados tanto en las estelas grabadas como en las pinturas rupestres de carros, guerrero tocado y posibles estelas pintadas que encontramos en los yacimientos Buitres $X$ y Pez II (Fig. 18) (Martínez Perelló, 1999).

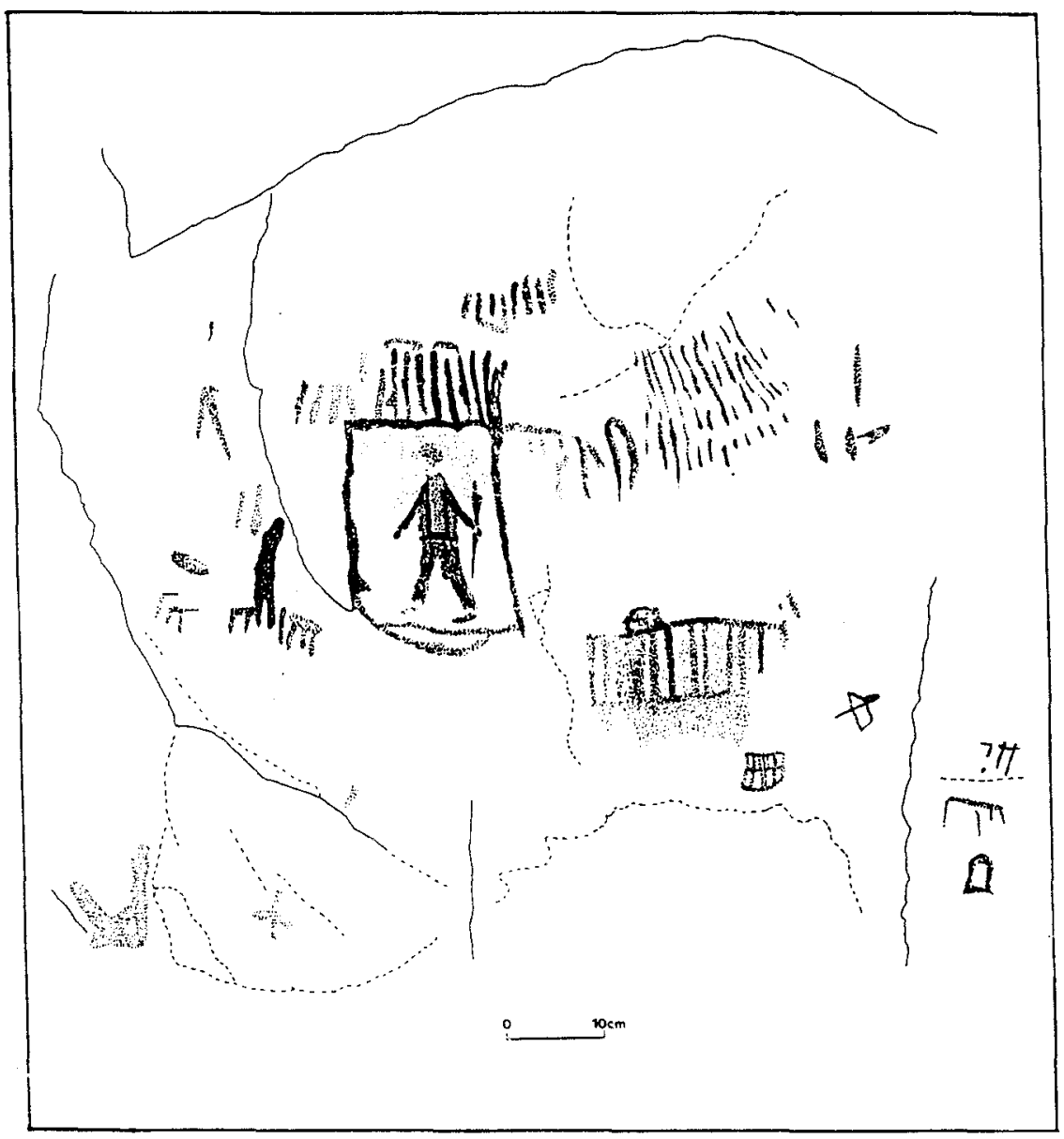

Fig. 18. Posible representación pictórica de estela en Pez II bajo representaciones actuales, como el «pistolero» con tirantes pintada sobre un antropomorfo anterior. 


\section{BIBLIOGRAFIA}

Acosta, P. (1968): La pintura rupestre esquemática en España, Memorias del Seminario de Prehistoria y Arqueología de la Universidad de Salamanca, Salamanca.

- (1984): «El arte rupestre esquemático ibérico: problemas de cronología preliminares", Scripta Praehistorica, Francisco Jordá, Oblata, Salamanca, págs. 31-61.

Almagro Basch, M. (1947): «Arte Prehistórico», Ars Hispaniae, t.1, Madrid, págs. 107-110. - (1966): Las estelas decoradas del Suroeste Peninsular, Bibliotheca Praehistorica Hispana, VIII, Madrid.

Almagro Gorbea, M. (1977): El Bronce Final y el Periodo Orientalizante en Extremadura, Bibliotheca Praehistorica Hispana, XIV, Madrid.

Beltrán Martínez, A. (1989): Ensayo sobre el origen y significación del arte prehistórico, Prensas Universitarias, Zaragoza.

BLAZquez Martínez, J.M. (1955-56): «Los carros votivos de Mérida y Almorchón. Su significación religiosa», Zephyrus, VI-VII, págs. 41-60.

BRADLEY, R. (1991): «Rock Art and the Perception of Landscape», Cambridge Archaeological Journal, 1, págs. 77-101.

BREUIL, H. (1933): Les peintures rupestres schématiques de la Péninsule lbérique, t.II, Foundation Singer-Polignac, Lagny.

Breuil, H. y BuRkITT, M. (1929): Rock paintings of southern Andalusia. A description of a Neolithic and Copper Age art group, Clarendon Press, Oxford.

Bueno Ramírez, P. et alii (1984): «Tres nuevas estelas del Suroeste», Revista de Estudios Extremeños, 40,3, págs. 477-483.

CABRÉ, J. (1941): «Pinturas y grabados rupestres, esquemáticos, de las provincias de Soria y Segovia», Archivo Español de Arqueología, XLIII, págs. 316-344.

Castaños UGarte, P.M. (1991): «Animales domésticos y salvajes en Extremadura. Origen y evolución», Revista de Estudios Extremeños, XLVII, n. ${ }^{\circ}$ 1, págs. 9-67.

EnRIQuez Navascués, J.J. y Jimenez Aparicio, E. (1989): Las tierras de Mérida antes de los romanos (Prehistoria de la comarca de Mérida), Mérida.

Fernández-Miranda, M. y Olmos, R. (1986): Las ruedas de Toya y el origen del carro en la Península Ibérica, Catálogos y Monografías del Museo Arqueológico Nacional, 9, Ministerio de Cultura, Madrid.

Galán Domingo, E. (1993): Estelas, Paisaje y Territorio en el Bronce Final del Suroeste de la Península Ibérica, Complutum Extra, 3, Madrid.

Galán Domingo, E. y Martín Bravo, A. (1991-92): «Megalitismo y zonas de paso en la cuenca extremeña del Tajo», Zephyrus, 44-45, págs. 193-205.

Grande del Brío, R. y Gonzalez-Tablas SASTRE, F.J. (1983): «Imagen y símbolo en el arte rupestre esquemático», Actas del Coloquio Internacional sobre Arte Esquemático en la Península Ibérica, Salamanca, 1982, Zephyrus, XXXVI, págs. 193-194.

HeRnÁndez-PACHECO, E. (1918): «Estudios de arte prehistórico: 1. Prospección de las pinturas rupestres de Morella la Vieja. Il. Evolución de las ideas madre de las pinturas rupestres", Comisión de Investigaciones Paleontológicas y Prehistóricas, Memoria n. ${ }^{\circ} 16$, Madrid.

Hurtado, V. (1995a): El Calcolítico a debate: reuniones del Calcolítico de la Península Ibérica, Sevilla.

- (1995b): «Interpretación sobre la dinámica cultural en la cuenca media del Guadiana (IV-ll milenio A.N.E.)», Extremadura Arqueológica, V, Cáceres-Mérida, págs. 53-80.

IGLESIAS GIL, J.L. (1980): «Estela inédita hallada en El Viso (Córdoba)», Archivo Español de Arqueología, 53, págs. 189-193.

- (1980): «Nueva estela procedente de El Viso (Córdoba)», Zephyrus, 30-31, págs. 254256.

JORDÁ, F. (1983): «Introducción a los problemas del arte esquemático de la Península Ibérica», Actas del Coloquio Internacional sobre Arte Esquemático de la Península Ibérica, Salamanca, 1982, Zephyrus, XXXVI, págs. 7-12.

KüHN, H. (1957): El arte rupestre en Europa, Barcelona.

Martinez Perelló, M.I. (1988-89): «Un nuevo conjunto de pintura esquemática en la Sierra del Pedroso (Peñalsordo y Capilla, Badajoz)", Ars Praehistorica, VII-VIII, págs. 201219 . 
- (1993a): «Arte rupestre en Badajoz. Un nuevo abrigo con pinturas esquemáticas: el Morro del Valle de la Venta (Cabeza del Buey)", Revista de Estudios Extremeños, XLIX, págs. 309-336.

- (1993b): “La investigación de la pintura rupestre esquemática en Extremadura», I Congreso de Arqueología Peninsular (Oporto, 1993), Trabalhos de Antropologia e Etnologia, XXXIII, fasc. 3-4, págs. 185-197.

- (1994): «La pintura rupestre esquemática en la zona oriental de la provincia de Badajoz: estado de la cuestión", Espacio, Tiempo y Forma, serie 1, t. 6, págs. 97-132.

- (1995): «Los abrigos pintados de Helechal: Un nuevo conjunto de arte rupestre esquemático en Badajoz", Espacio, Tiempo y Forma, serie I, t. 8, págs. 191-233.

- (1999): La pintura rupestre esquemática en Extremadura sudoriental, Tesis Doctoral, Universidad Nacional de Educación a Distancia (edición microfilmada).

Martínez Perello, M.I. y Collado Giraldo, H. (1997): "Arte rupestre esquemático en la provincia de Badajoz", Jornadas sobre Arte Rupestre en Extremadura (Cáceres, 1997), Extremadura Arqueológica, VII, págs. 151-173.

Nieto Gallo, G. (1983): «Introducción a la Tesis Doctoral de Caballero Klink, A.», La pintura rupestre esquemática de la vertiente septentrional de Sierra Morena (provincia de Ciudad Real), y su contexto arqueológico, Estudios y Monografías, 9, Ciudad Real.

- (1985): «La Península Ibérica al final del Il y comienzos del I milenio a.C. hasta la aparición del Hierro», Historia General de España y América: los orígenes de España, t. I, De. Rialp, Madrid, págs. 429-500.

Ortiz, M. y Muñoz-Torrero, E. (1995): Pinturas rupestres en la Sierra Grajera (Mérida), Extremadura Arqueológica, V, págs. 39-51.

PAstor Muñoz, M. et alii (1992): Miróbriga. Excavaciones arqueológicas en el "Cerro del Cabezo" (Capilla, Badajoz). Campañas 1987-88, Consejería de Educación y Cultura, Junta de Extremadura, Mérida.

PAvón Soldevilla, I. (1994): Aproximación al estudio de la Edad del Bronce en la Cuenca Media del Guadiana: la solana del castillo de Alange (1987), Institución Cultural «EI Brocense», Diputación Provincial de Cáceres, Cáceres.

- (1995): «La Edad del Bronce», Extremadura Arqueológica, IV, págs. 35-65.

Ripoll Peret.ló, E. (1968): "Cuestiones en torno a la cronología del arte rupestre postpaleolítico en la Península Ibérica», Simposio Internacional de Arte Rupestre (Barcelona, 1966), Instituto de Prehistoria y Arqueología de la Diputación Provincial de Barcelona, págs. 165192.

Rodriguez Diaz, A. (1989): "La Segunda Edad del Hierro en la Baja Extremadura: problemática y perspectivas en torno al poblamiento", Saguntum, 22, págs. 165-224.

- (1995): «Extremadura Prerromana», Extremadura Arqueológica, IV, págs. 91-121.

- (coord.) (1998): Extremadura Protohistórica: Paleoambiente, economía y poblamiento, Cáceres.

RuIz-Gálvez Priego, M. (1986): «Navegación y comercio entre el Atlántico y el Mediterráneo a fines de la Edad del Bronce», Trabajos de Prehistoria, 43, págs. 9-42.

- (1987): "Bronce Atlántico y "cultura" del Bronce Atlántico en la Península Ibérica», Trabajos de Prehistoria, 44, págs. 251-264.

- (1988): «Oro y política. Alianzas comerciales y centros de poder en el Bronce Final del occidente peninsular», Homenaje al Prof. Ripoll Perelló, Espacio, Tiempo y Forma, serie 1, t. I, págs. 325-338.

- (1989): «La orfebrería del Bronce Final. El poder y su ostentación», El oro en la España prerromana, Ed. Zugarto, Madrid, págs. 46-57.

- (1990): "Canciones del Muchacho Viajero", Veleia, 7.

- (1991): "Orfebrería, poder y sociedad en la Península durante el Bronce Fina|», Seminario "Orfebrería prerromana en la Península lbérica", Madrid.

- (1992): "La novia vendida: orfebrería, herencia y agricultura en la protohistoria de la Península Ibérica», SPAL, I, Sevilla, págs. 219-251.

- (1993): «El Occidente de la Península Ibérica, punto de encuentro entre el Mediterráneo y el Atlántico a fines de la Edad del Bronce», Complutum, 4, Madrid, págs. 41-68.

SANCHEZ-GÓMEZ, J.L. (1983): «Acerca de la coloración en las pinturas rupestres prehistóricas», Actas del Coloquio Internacional sobre Arte Esquemático de la Península Ibérica, Salamanca, 1982, Zephyrus, XXXVI, Salamanca, págs. 245-253. 
VAQUERIzo GIL, D. (1985): “Dos nuevas estelas de guerrero en la provincia de Badajoz», XVII Congreso Nacional de Arqueología (Logroño, 1983), Zaragoza, págs. 465-472.

- (1986): "Indigenismo y romanización en la llamada Siberia extremeña», Revista de Arqueología, 58, Madrid, págs. 10-18. 